\title{
A APLICAÇÃO DE TECNOLOGIAS DIGITAIS NO CANTO CORAL DE ADULTOS E SUAS MÚLTIPLAS POSSIBILIDADES
}

\author{
Digital technologies applied to adult choir \\ singing and its multiple possibilities
}

\author{
Tecnologías digitales aplicadas al canto coral \\ de adultos y sus múltiples posibilidades
}

\author{
SANDRA Regina Cielavin \\ Universidade Estadual de Campinas \\ cielavsandra@gmail.com \\ Adriana N. A. Mendes \\ Universidade Estadual de Campinas \\ aamend65@gmail.com
}

\begin{abstract}
Resumo: Este artigo é um recorte de uma dissertação de mestrado que teve por objetivo investigar tecnologias digitais que contribuam com a formação do regente e com o desenvolvimento da prática coral de adultos. O referencial teórico utilizado foi o modelo do Conhecimento Tecnológico Pedagógico e de Conteúdo (TPACK) proposto por Mishra e Koehler (2006). A metodologia consistiu no estudo de métodos mistos através de uma pesquisa-ação com 18 integrantes de um coro adulto durante três meses. A coleta de dados foi efetuada por meio de um diário de campo, do registro das atividades dos coristas e da aplicação de um questionário no início e no final da pesquisa. A análise dos dados evidenciou que o uso das tecnologias digitais contribuiu com o desenvolvimento da percepção musical dos integrantes e com a ampliação do universo musical e cultural do coro. Considerou-se que as tecnologias digitais podem colaborar com a organização do coro, bem como oferecer múltiplas possibilidades de atividades de estudos musicais.
\end{abstract}

Palavras-chave: Educação musical. Canto coral. Tecnologia da informação e comunicação.

\begin{abstract}
This article is a clipping of a master's dissertation that aimed to investigate digital technologies that contribute to the formation of the conductor and the development of the choral practice of adults. The theoretical framework used was the Technological Pedagogical Content Knowledge (TPACK) model proposed by Mishra and Koehler (2006). The methodology consisted of the study of mixed methods through an action research with 18 members of an adult choir for 3 months. Data collection was done through a field diary, recording the activities of the choir singers and applying a questionnaire at the beginning and end of the research. The data analysis showed that the use of digital technologies contributed to the development of the musical perception of the members and the expansion of the musical and cultural universe of the choir. It was considered that digital technologies can collaborate with the organization of the choir, as well as offer multiple possibilities of musical studies activities.
\end{abstract}

Keywords: Music education. Choral singing. Information and communication technology.

Resumen: Este artículo es un recorte de una disertación de maestría que tuvo como objetivo investigar tecnologías digitales que contribuyen a la formación del director y al desarrollo de la práctica coral de adultos. El marco teórico utilizado fue el modelo de Conocimiento Técnico Pedagógico del Contenido (TPACK) propuesto por Mishra y Koehler (2006). La metodología consistió en el estudio de métodos mixtos a través de una investigación-acción con 18 miembros de un coro de adultos durante 3 meses. La recolección de datos se realizó a través de un diario de campo, registrando las actividades de los cantantes del coro y la aplicación de un cuestionario al comienzo y al final de la investigación. El análisis de datos mostró que el uso de tecnologías digitales contribuyó al desarrollo de la percepción musical de los integrantes y a la expansión del universo musical y cultural del coro. Se consideró que las tecnologías digitales pueden colaborar con la organización del coro, así como ofrecer múltiples posibilidades de actividades para el estudio de la música.

Palabras clave: Educación musical. Canto coral. Tecnología de la información y la comunicación. 


\section{INTRODUÇÃO}

As tecnologias da informação e comunicação (TIC) têm se tornado parte da sociedade atual nos mais diversos campos do conhecimento. Segundo Demo (2011, p. 15), "as ferramentas tecnológicas estão se impondo veloz e compulsoriamente na nova geração, tornando-se parte do dia a dia". Na atualidade, os estudantes estão assumindo um papel mais participativo em seus ambientes de aprendizagem (Demo, 2011; Keri; Selwyn, 2010).

Esta pesquisa teve por objetivo investigar tecnologias da informação e comunicação que sirvam de suporte ao regente, que contribuam com a sua formação e com o desenvolvimento da prática coral de adultos. Detecta-se que existe uma lacuna de estudos e de projetos relacionados à aplicação de tecnologias digitais na educação musical, notadamente em contextos relacionados à prática coral como apontam os levantamentos de Santos (2014), Mateiro, Vechi e De Souza Egg (2014) e Clemente e Figueiredo (2014). Esses levantamentos trazem temas tais como técnica vocal, repertório, regência coral, canto em atividades escolares extramusicais, entre outros. No entanto, não discutem a utilização de tecnologias digitais em suas práticas.

Neste trabalho, para definição das TIC foi considerado o conceito de novas tecnologias de informação e comunicação (NTIC), que segundo Velloso (2014) englobam os equipamentos físicos, as tecnologias de som e vídeo digital, os programas de computador e a internet com todo o seu conjunto de serviços, tais como: páginas, armazenamento, download, entre outros.

Freitas e Conole (2010) indicam que em relação às TIC no processo de aprendizagem, o foco não deveria estar nas ferramentas, mas em como elas podem ser utilizadas. Qualquer intervenção de aprendizagem consiste em quatro partes: pensamento e reflexão, conversação e interação, experiência e atividade e evidência e demonstração ${ }^{1}$ (Freitas; Conole, 2010, p. 25).

\section{O CANTO CORAL E OS ASPECTOS DE PERCEPÇÃO E PRODUÇÃO MUSICAL}

O canto coral é uma atividade que possibilita o desenvolvimento de diversos aspectos musicais. Indivíduos adultos que ingressam na prática do canto coral podem trazer diferentes experiências musicais e apresentar dificuldades de afinação, de manutenção de sua linha vocal, de ritmo, entre outras. Swanwick (1979, p. 42, tradução nossa) afirma que as "pessoas precisam de múltiplas oportunidades de encontros com a música para experimentá-la de diferentes ângulos de forma a tornarem-se conscientes de sua riqueza de possibilidades". ${ }^{2}$ Ao oferecer amplas oportunidades que promovam a apren-

\footnotetext{
1 “[...] Learning process, enabling the learner to focus not so much on the tools but how they are being used. Any learning intervention consists of four interrelated facets: thinking and reflection, conversation and interaction, experience and activity, evidence and demonstration."

2 "People need multiple opportunities for meeting up with music, homing in from different angles in order to become aware of its richness of possibilities."
} 
dizagem musical, o regente poderá contribuir com o desenvolvimento da percepção e da produção musical dos integrantes de seu coro.

A percepção musical está ligada à audição. Schafer (1991, p. 67) indica que "ao contrário de outros órgãos dos sentidos, os ouvidos são expostos e vulneráveis. Os olhos podem ser fechados se quisermos; os ouvidos não, estão sempre abertos." De acordo com Levitin (2006) quando ouvimos música notamos sete dimensões diferentes, dentre as quais estão o ritmo, a altura e o andamento. Quanto às propriedades de altura e ritmo, Krumhansl (2006, p. 46) ressalta que "a informação perceptiva é assimilada a esses esquemas, o que facilita a organização dos eventos sonoros em padrões e gera expectativas de eventos futuros".

O cérebro armazena e recupera informações da memória. No entanto, se este não for devidamente estimulado pode não funcionar adequadamente. Quanto à memória musical e o seu desenvolvimento, Sobreira (2003, p. 67) sugere que existe a possibilidade de que a falta de exposição à música seja um importante fator relacionado à capacidade de reter e produzir eventos musicais.

Quanto à produção vocal Ilari (2003, p. 15) aponta que "o ato de cantar, espontaneamente ou de forma dirigida em sala de aula, pode ativar os sistemas da linguagem, da memória, e de ordenação sequencial, entre outros". No entanto, Sobreira (2003) assinala que a emissão vocal pode ser prejudicada devido a problemas respiratórios, dificuldade de reprodução de intervalos e de ritmo, uso inadequado do registro vocal, entre outros.

\section{CONHECIMENTO TECNOLÓGICO PEDAGÓGICO E DE CONTEÚDO (TPACK)}

As TIC podem ser uma ferramenta bastante útil ao educador musical, sobretudo para o regente coral no que se refere à organização, administração, desenvolvimento da percepção musical e ampliação do universo musical do coro. Devido à rapidez com que as tecnologias digitais se modificam é possivel que o educador não tenha conhecimento, não esteja atualizado ou familiarizado com programas de computador e outros recursos tecnológicos que poderiam ser utilizados em sua prática de trabalho e de ensino. Nesse aspecto, Vincent e Merrion (1996, p. 40, tradução nossa) indicam que "educadores musicais precisam estar preparados para a emergente interação sofisticada entre o aluno e a música, o aluno e a tecnologia e o aluno e o professor". 3

O referencial teórico utilizado nesta pesquisa foi o modelo do Conhecimento Tecnológico Pedagógico e de Conteúdo (TPACK) ${ }^{4}$ proposto por Mishra e Koehler (2006). O modelo foi fundamentado nos estudos de Lee Shulman, no qual o professor integra o conhecimento do conteúdo ao conhecimento

\footnotetext{
3 "Music educators need to be prepared for the emerging sophisticated interaction between the learner and music, the learner and technology, and the learner and teacher."

4 Technological Pedagogical Content Knowledge.
} 
pedagógico e tem sido utilizado em áreas tais como matemática, história, ciências e música. A partir deste modelo, Mishra e Koehler (2006) incluíram o conhecimento tecnológico e suas associações com os outros dois conhecimentos. O modelo TPACK é formado pela intersecção de três círculos, como indica a Figura 1.

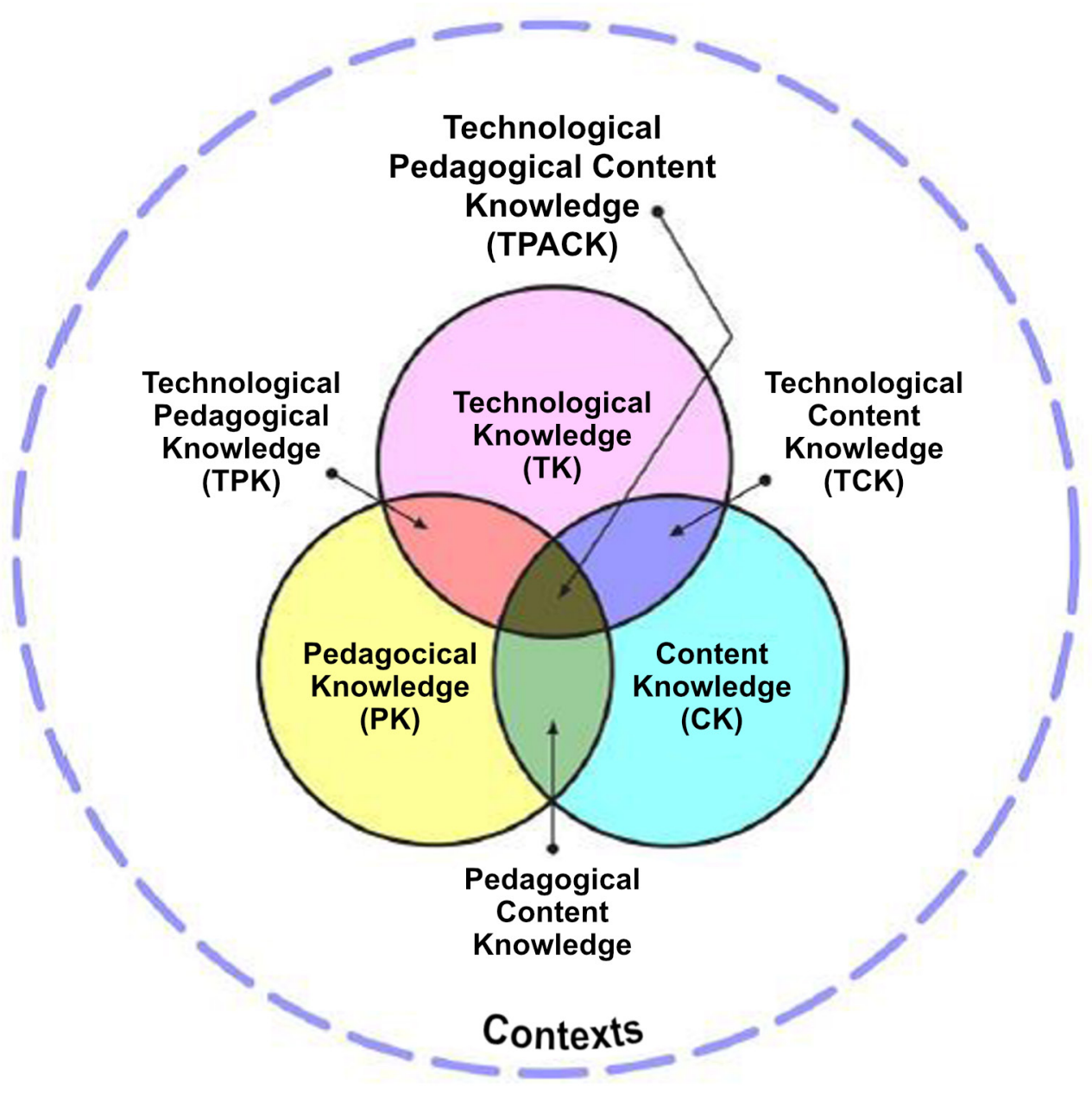

Figura 1: Conhecimento Tecnológico Pedagógico e de Conteúdo ("The TPACK framework and its knowledge components" - Koehler; Mishra, 2009, p. 63).

Os três círculos e suas intersecções serão descritos a seguir a partir das considerações de Koehler e Mishra (2009). O Conhecimento do Conteúdo (CK $)^{5}$ refere-se ao conhecimento do professor sobre teorias, conceitos e práticas de uma determinada disciplina e foi proposto por Lee Shulman. É imprescindível que o professor tenha uma base sólida sobre o assunto a ser estudado.

\footnotetext{
5 Content Knowledge.
} 
Na perspectiva da educação musical, sobretudo do canto coral, o Conhecimento do Conteúdo está associado aos conhecimentos musicais, vocais e de técnicas de regência pertinentes ao desenvolvimento desta atividade.

O Conhecimento Pedagógico $(\mathrm{PK})^{6}$ é a forma como o professor apreende e trabalha com as práticas e os métodos de ensino e aprendizagem. Esse conceito busca entender como os individuos aprendem e procura estabelecer e desenvolver estratégias de ensino e de planejamento de aulas e avaliações. Nesse conhecimento é essencial que o educador compreenda as teorias da aprendizagem e esteja atento aos aspectos motivacionais dos estudantes.

O Conhecimento Pedagógico do Conteúdo $(\mathrm{PCK})^{7}$ é a intersecção entre o Conhecimento do Conteúdo e o Conhecimento Pedagógico. A aplicação desse conceito é concretizada quando o educador procura fazer adaptações de materiais, busca diferentes estratégias de ensino e considera o conhecimento trazido pelos estudantes. No canto coral, o regente precisa conectar o conhecimento pedagógico ao conhecimento de conteúdo para dar sentido ao repertório e às práticas musicais vivenciadas pelo coro.

Koehler e Mishra (2009) definem o Conhecimento Tecnológico (TK) ${ }^{8}$ como a compreensão sobre tecnologia da informação e a forma como ela poderia ser aplicada produtivamente no cotidiano e no trabalho dos individuos. O Conhecimento Tecnológico supõe atualização e adaptação contínuas devido à rapidez das mudanças ocorridas na atualidade.

A intersecção entre o Conhecimento Tecnológico e o Conhecimento do Conteúdo é o Conhecimento Tecnológico do Conteúdo (TCK). ${ }^{9}$ Esse conceito diz respeito ao entendimento sobre as relações de influência e restrições entre a tecnologia e o conteúdo e inclui a percepção sobre a escolha da tecnologia mais adequada para determinado propósito. Sobre a restrição da tecnologia, por exemplo, quando professor precisa realizar uma videoconferência com os alunos é necessário utilizar o Skype ou o Google Hangouts; o correio eletrônico ou outra tecnologia assíncrona não seria adequada para essa finalidade.

O Conhecimento Tecnológico Pedagógico $(\mathrm{TPK})^{10}$ refere-se à reconfiguração, personalização e ao reaproveitamento de tecnologias que embora não tenham sido projetadas com finalidades educacionais podem ser utilizadas com propósitos pedagógicos. O programa Microsoft Office Suite (Word, Excel, PowerPoint e MSN Messenger), concebido para uso de empresas, por exemplo, pode ser utilizado para fins educacionais.

A intersecção que engloba os três círculos é o Conhecimento Tecnológico Pedagógico e de Conteúdo (TPACK). ${ }^{11} \mathrm{O}$ modelo TPACK é a integração entre

\footnotetext{
Pedagogical Knowledge.

Pedagogical Content Knwoledge.

Technological Knowledge.

Technological Content Knowledge.

10 Technological Pedagogical Knowledge.

11 Technological Pedagogical Content Knowledge.
} 
os três Conhecimentos. Koehler e Mishra (2009, p. 66, tradução nossa) afirmam que o

TPACK é a base de um ensino eficaz com tecnologia, exigindo um entendimento da representação de conceitos utilizando tecnologia; técnicas pedagógicas que utilizam tecnologias de formas construtivas para ensinar conteúdos; [...] [levando em conta o] conhecimento de teorias epistemológicas e o conhecimento prévio dos alunos. Os professores precisam desenvolver fluência e flexibilidade cognitiva não somente em cada um dos domínios ( $\mathrm{T}, \mathrm{P}$ e C), mas também na maneira como esses domínios se entrelaçam para que possam construir soluções efetivas. ${ }^{12}$

\section{PROCEDIMENTOS METODOLÓGICOS}

A metodologia do estudo consistiu em pesquisa bibliográfica, no levantamento e na descrição de atividades com possiveis utilizações de tecnologias digitais no canto coral. Foi realizado um estudo de métodos mistos através de uma pesquisa-ação. Segundo Creswell (2010), nas ciências sociais e humanas, a pesquisa de métodos mistos faz a combinação de abordagens qualitativas e quantitativas. Tripp (2005, p. 445) mostra que a pesquisa-ação é "uma estratégia para o desenvolvimento de professores e pesquisadores de modo que eles possam utilizar suas pesquisas para aprimorar seu ensino e, em decorrência, o aprendizado de seus alunos".

O grupo investigado é o coral da Faculdade de Tecnologia de Itapetininga, que é formado por alunos, professores e membros da comunidade. Os ensaios ocorrem duas vezes por semana e têm duração de uma hora e meia. O repertório é composto de canções tradicionais de diferentes países, música popular brasileira, música pop internacional e músicas natalinas. A pesquisa contou com a participação de 18 integrantes durante três meses e foi aprovada pelo Comitê de Ética da Universidade Estadual de Campinas (Unicamp).

No desenvolvimento da pesquisa-ação e na aplicação das TIC, a pesquisadora assumiu o papel de regente e de proponente das atividades. Além disso, atuou na instalação de programas no laboratório de informática e na criação da sala virtual Google Classroom. Nos primeiros ensaios foi oferecido um treinamento no laboratório de informática para utilização da sala virtual e para que os participantes recebessem orientações sobre o uso dos programas. As atividades tecnológicas foram propostas nos ensaios presenciais e no ambiente virtual.

O local escolhido possui laboratório de informática e salas de aula equipadas com computador de mesa, projetor multimidia, caixas de som e acesso

\footnotetext{
12 "TPACK is the basis of effective teaching with technology, requiring an understanding of the representation of concepts using technologies; pedagogical techniques that use Technologies in constructive ways to teach content; [...]; knowledge of students' prior knowledge and theories of epistemology. Thus, teachers need to develop fluency and cognitive flexibility not just in each of the key domains (T, P and C), but also in the manner in which these domains and contextual parameters interrelate, so that they construct effective solutions."
} 
à internet. As atividades presenciais com o uso das TIC foram desenvolvidas no laboratório de informática e na sala de aula em dias alternados, mas sempre no início dos ensaios. Quanto ao perfil dos participantes, 14 são do sexo feminino e 4 do sexo masculino, 6 são jovens entre 21 e 29 anos, 9 são adultos entre 30 e 59 anos e 3 estão acima de 60 anos. Na análise dos dados, os 18 coristas foram denominados pela letra $\mathrm{C}$ seguida de um número e a regente, pela letra $R$. Observa-se que, antes da aplicação das tecnologias digitais, 0 coral não fazia uso de programas ou da internet para fins de aprendizagem musical.

A coleta de dados foi efetuada por meio de um diário de campo, do registro dos comentários e das atividades desenvolvidas pelos coristas nos ambientes presencial e virtual, de gravações dos ensaios, do controle de presença, de trechos de conversas do WhatsApp e da aplicação de um questionário composto de 24 questões, em dois momentos: no início e no final da pesquisa. No final da coleta somente as questões relacionadas à aprendizagem musical e à utilização das TIC foram reaplicadas.

O questionário foi elaborado pela pesquisadora e discutido com a orientadora. As questões foram disponibilizadas através de um link no Google Forms ${ }^{13}$ e foram respondidas no laboratório de informática. Sobre o tipo de questões, Gil (2007) afirma que podem ser fechadas, que apresentam um conjunto de alternativas de resposta; abertas, que deixam um espaço em branco para a resposta; e dependentes, que estão vinculadas à resposta da questão anterior. Quanto às questões, 16 foram formuladas com alternativas de múltipla escolha e 8 com espaço para respostas abertas. As 4 questões iniciais são sobre dados pessoais, as questões de 5 a 8 estão relacionadas à motivação e participação no coral, as questões de 9 a 13 abordam o desenvolvimento da percepção musical, as questões 15 e 16 trazem perguntas sobre o regente coral e as questões 14 e de 17 a 24 têm por objetivo investigar a ampliação do universo musical e cultural do coro e a utilização das tecnologias digitais.

\section{AS TECNOLOGIAS DIGITAIS PROPOSTAS NO ESTUDO}

O levantamento realizado teve por objetivo investigar e descrever TIC que contribuam com a formação do regente e com o desenvolvimento da prática coral; contudo, a aplicação das TIC não tem o intuito de substituir o regente, ou os ensaios presenciais, mas de apontar formas de emprego das tecnologias digitais que poderiam contribuir trazendo mais agilidade na preparação e execução de atividades, velocidade na comunicação e no compartilhamento de diferentes tipos de arquivos pertinentes ao canto coral. Miletto, Costalonga, Flores, Fritsch, Pimenta e Vicari (2004) indicam que a utilização dos computadores na educação musical tem duas premissas: não se pretende substituir o professor, mas sim oferecer mais uma possibilidade em sua prática de ensino, e o professor deve decidir como fará a aplicação dos recursos computacionais.

\footnotetext{
${ }^{13}$ Serviço gratuito para criar formulários on-line.
} 
$\mathrm{Na}$ aplicação das TIC seria essencial privilegiar a reflexão. Para o educador musical Hans-Joachim Koellreutter, "educar, era parte complementar - e fundamental - de um todo, implicando, acima de tudo, conscientizar. O professor não ensina nada; ele sempre conscientiza" (Brito, 2016, p. 148).

As atividades foram planejadas e aplicadas de forma gradual nos ensaios presenciais e no ambiente virtual. Dentre as tecnologias digitais empregadas na pesquisa estão o serviço de compartilhamento de vídeos YouTube, o editor de áudio Audacity, o programa de notação musical MuseScore, o software de percepção musical GNU ${ }^{14}$ Solfege $^{15}$ e o reprodutor de mídia Windows Media Player. Sobre os programas musicais aplicados no estudo optou-se pela utilização de software livre pela liberdade de serem estudados, executados, distribuídos e melhorados. Portanto, todos os participantes da pesquisa puderam ter acesso aos programas sem a necessidade de adquirirem uma licença de uso. Além dos programas descritos neste trabalho, o levantamento proposto na dissertação apresenta outros programas, tais como o LenMus, o WaveSurfer, entre outros.

Quanto à ampliação do repertório musical, Schafer (1991, p. 296) ressalta que é essencial estudar a música de outras culturas. Bauer e Mito (2017) evidenciam que serviços como o YouTube e o Spotify expandiram as oportunidades de acesso à música, e de acordo com Doebele (2012), além do compartilhamento de vídeos, o YouTube permite a criação de canais. No estudo proposto, o uso do YouTube consistiu em uma atividade on-line na qual foram postadas sequencialmente tarefas de escuta e de pesquisa da música coral dos períodos que foram da Renascença ao pós-modernismo.

Segundo Gohn (2010, p. 18) o editor de áudio permite "processar o som de diversas maneiras, aplicando uma enorme lista de efeitos, que pode incluir compressão, reverberação, delay, normalização, eco, alteração de altura e tempo, aumento de graves".

A utilização do editor de áudio Audacity ${ }^{16}$ teve por objetivo a gravação da voz do corista e a exploração de diferentes efeitos sonoros em canções do repertório, como alteração do tom e do andamento. Além disso, os integrantes estudaram o arranjo para quatro vozes da música Joyful, joyful, we adore thee de Ludwig van Beethoven e letra de Henry Jackson van Dyke que foi gravado em quatro faixas no programa. Nos ensaios presenciais o Audacity foi utilizado para realizar gravações dos ensaios presenciais seguidas por reflexões e comentários dos coristas e da regente sobre o que poderia ser melhorado ou modificado. O Windows Media Player foi empregado para que o coro

\footnotetext{
${ }^{14}$ O projeto GNU foi lançado para desenvolver o sistema operacional livre GNU (um acrônimo para "GNU's Not Unix" - "Gnu não é Unix"). GNU é software livre e nesse conceito os usuários possuem a liberdade de executar, copiar, distribuir, estudar, mudar e melhorar o software.

15 Programa de treinamento auditivo que possibilita o contato com figuras musicais, intervalos e acordes. Possui o recurso de exportar exercícios no formato de áudio. Disponível em: https://sourceforge.net/projects/solfege/?source=directory.

${ }^{16}$ O programa funciona nos sistemas operacionais Microsoft Windows, Linux e Mac OS e permite a exportação de arquivos de áudio no formato mp3. Disponível em http://www.audacityteam.org.
} 
assistisse a gravações de coros-referência e as gravações do próprio coro de forma presencial com o intuito de observar, analisar e dialogar sobre diferentes aspectos.

O programa MuseScore ${ }^{17}$ tem recebido atualizações constantes e permite a exportação de arquivos de áudio em diferentes formatos. O propósito do MuseScore foi oferecer aos coristas a possibilidade de aprender as notas da clave de sol, conhecer as figuras musicais, criar melodias curtas de forma colaborativa no ensaio presencial com a orientação da regente e estudar as canções do repertório do coral.

O software de treinamento auditivo GNU Solfege foi empregado como um jogo musical nos ensaios presenciais em atividades relacionadas ao ritmo, nas quais o coral foi dividido em dois grupos que precisavam acertar a sequência correta das figuras musicais distribuídas no compasso. Bauer (2014, p. 97-98) aponta que identificar e interpretar simbolos musicais e valores rítmicos e ler uma partitura de forma cantada são atividades que podem ser aplicadas com um programa de teoria musical.

A tecnologia escolhida para integrar as atividades no ambiente virtual foi o Google Classroom. ${ }^{18}$ Sobre a utilização de sistemas on-line Salavuo (2008, p. 127, tradução nossa) salienta que:

As atividades realizadas em comunidades on-line de música incluem o upload de música por um membro do grupo e a espera de comentários, a apreciação de músicas que tenham sido compartilhadas pelos outros integrantes, discussão, perguntas e respostas pertinentes à música que envolvam argumentos, a sugestão de músicas e o envolvimento em projetos. ${ }^{19}$

O Google Classroom foi escolhido por ser um ambiente já utilizado na faculdade onde a pesquisa foi realizada, bem como pelo fato de a pesquisadora poder criar a sala de aula virtual do coral com o e-mail institucional. Nessa plataforma os estudantes podem ser adicionados através de convite no e-mail ou pela inserção de um código para aquela turma específica. O Google Classroom possui um mural de comunicações e pode ser organizado em tópicos tais como: Atividade, Material e Pergunta. O ambiente está em constante atualização e está conectado com o Google Agenda ${ }^{20}$ e com o Google Drive. ${ }^{21}$

\footnotetext{
17 Software que permite criar e editar uma partitura musical. Pode ser instalado nos ambientes Linux, Windows e Mac OS. Disponível em: https://musescore.org/pt-br.

${ }_{18}$ Sala de aula virtual que permite a postagem de material e criação de tarefas com prazo de entrega. Disponível em: http://classroom.google.com.

19 "Activities in online music communities include. Uploading one's own music, expecting feedback. Listening to music contributed by peers, providing feedback. Discussing, asking questions, providing answers, engaging in arguments, recommending music, connecting together to engage in joint project."

${ }^{20}$ Serviço de agenda e calendário on-line.

${ }^{21}$ Serviço de armazenamento e compartilhamento de arquivos.
} 
No ambiente Google Classroom o material foi criado, organizado e disponibilizado em forma de arquivos de estudo e de tarefas para os coristas como demonstra o Quadro 1 a seguir.

\begin{tabular}{|c|c|}
\hline \multicolumn{2}{|r|}{ Atividades virtuais: Semana 5} \\
\hline Tarefa & Descrição \\
\hline $\begin{array}{l}\text { Conhecendo e explo- } \\
\text { rando os programas } \\
\text { Audacity e LenMus }\end{array}$ & $\begin{array}{c}\text { Explicações sobre o editor de áudio Audacity e sobre o } \\
\text { software de percepção musical LenMus, incluindo os links de } \\
\text { instalação dos programas, bem como o link do manual do } \\
\text { Audacity e um arquivo no formato PDF com dicas sobre o } \\
\text { LenMus. }\end{array}$ \\
\hline $\begin{array}{l}\text { MuseScore - Atividade } \\
\text { de criação/estudo }\end{array}$ & $\begin{array}{l}\text { Atividade contendo três arquivos, um com as notas dó, ré } \\
\text { e mi e os outros dois com as melodias criadas pelo coral } \\
\text { para que ouvissem e cantassem durante a semana. }\end{array}$ \\
\hline $\begin{array}{l}\text { Audacity: } \\
\text { Você é o DJ }\end{array}$ & $\begin{array}{c}\text { O corista poderia escolher uma música de sua preferência, } \\
\text { abri-la no programa Audacity, aplicar os efeitos deseja- } \\
\text { dos, salvar e anexar no Classroom. Como auxilio para a } \\
\text { atividade, a tarefa continha um arquivo no formato PDF } \\
\text { com dicas no Audacity sobre onde clicar para realizar cada } \\
\text { passo. }\end{array}$ \\
\hline $\begin{array}{l}\text { YouTube - Ampliando } \\
\text { a cultura musical - } \\
\text { Renascimento }\end{array}$ & $\begin{array}{c}\text { Início de uma viagem pelo tempo. O coro deveria assistir } \\
\text { ao vídeo do coro Montecastello entoando Jesu rex admira- } \\
\text { bilis de Palestrina }{ }^{22} \text { e pesquisar sobre a música na época } \\
\text { do Renascimento, o compositor Giovanni da Palestrina e o } \\
\text { significado da letra. }\end{array}$ \\
\hline
\end{tabular}

Quadro 1: Atividades virtuais - Semana 5. Fonte: dados da pesquisa.

\section{CATEGORIZAÇÃO DOS DADOS}

Após a aplicação dos questionários, do registro no diário de campo e das atividades desenvolvidas pelos coristas nos ambientes presencial e virtual, os dados foram organizados e apresentados em três categorias: 1. Desenvolvimento da percepção musical; 2. Aspectos administrativos e organizacionais; e 3. Ampliação do universo musical e cultural do coro, que serão descritas a seguir.

\section{Desenvolvimento da percepção musical}

A análise da categoria 1 - Desenvolvimento da percepção musical - foi baseada nas aplicações dos programas Audacity e MuseScore no ambiente presencial e virtual e nas respostas dos questionários relacionadas a quais

\footnotetext{
${ }^{22}$ Disponível em: https://www.youtube.com/watch?v=EjsK-NJqsRs.
} 
habilidades musicais seriam essenciais ao corista e quais seriam as suas maiores dificuldades. Na questão 10 - "Como cantor do Coral em qual(is) item(ns) você percebe que tem mais dificuldade" - como demonstra a Figura 2, após a aplicação das tecnologias digitais, o item "Percepção auditiva" passou de 38,89\% para $72,22 \%$ das respostas, o que demonstrou que os integrantes entenderam a necessidade do desenvolvimento dessa habilidade no canto coral.

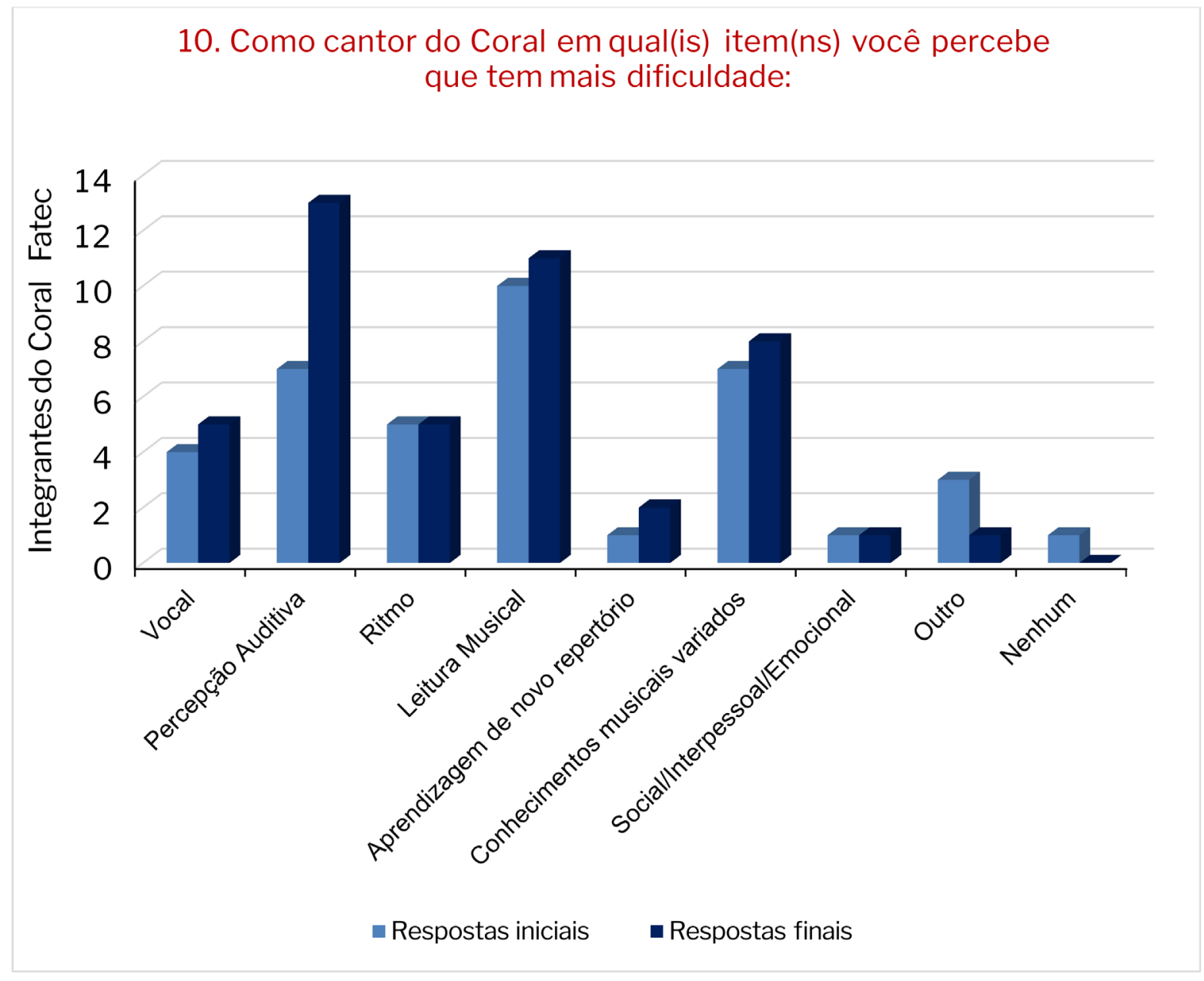

Figura 2: Resumo das respostas iniciais e finais da questão 10. Fonte: dados da pesquisa.

Os integrantes do coro possuem diferentes niveis de experiências musicais. No ambiente virtual, o Audacity foi proposto em atividades de gravações individuais, aplicação de efeitos em diferentes canções do repertório e estudo de uma canção com arranjo para quatro vozes. Todas as tarefas virtuais tiveram o feedback em comentários particulares da regente, que procurou inicialmente enfatizar pontos positivos das atividades entregues pelos coristas e depois dar sugestões sobre respiração, impostação vocal, entre outros. 
Na aplicação do programa MuseScore no ensaio presencial observou-se que três integrantes se interessaram muito em aprender a fazer a transposição de músicas e em saber de que forma essas modificações na partitura poderiam ser úteis em outras atividades em que participam como cantores, sendo que um deles atua como regente coral. Em atividades no ambiente virtual com a utilização do MuseScore notou-se comentários tais como: C7: "Não vejo a hora de criar minha primeira linha de partitura!"; C6: "Eu comecei fazer uma música que não terminei, só que eu a salvei e não sei onde. Chama teste 1. Foi no MuseScore"; C6: "Já achei e consegui mudar alguma coisa. Estou gostando da brincadeira. Muito interessante."

\section{Aspectos administrativos e organizacionais}

Na categoria 2 - Aspectos administrativos e organizacionais - foram analisadas as questões relacionadas às habilidades do regente coral e à importância das interações e do espírito colaborativo no coral. Além disso, foi considerado o material de arquivos $\mathrm{mp} 3$, partituras, tarefas, videos no YouTube, que foi disponibilizado aos coristas na sala virtual Google Classroom como mostra a Figura 3 a seguir e que permitiu a organização e o agrupamento de todos os recursos no mesmo ambiente, bem como funcionou como facilitador das interações, notadamente durante a semana.

\begin{tabular}{|c|c|}
\hline \multicolumn{2}{|l|}{ Canções Tradicionais - mp3 } \\
\hline $\begin{array}{l}\mathbf{5 8} \text { - Haida.mp3 } \\
\text { Áudio }\end{array}$ & \\
\hline $\begin{array}{l}59 \text { - A La Nanita Nana.mp3 } \\
\text { Áudio }\end{array}$ & \\
\hline \multicolumn{2}{|l|}{ Qual é a música? } \\
\hline $\begin{array}{l}\text { Coloque nos comentários dessa atividade, uma ou m } \\
\text { gostaria que fossem cantadas pelo Coral. Coloque } \\
\text { o (a) intérprete ou banda e um link do YouTube }\end{array}$ & $\begin{array}{l}\text { is músicas que você } \\
\text { nome da música, } \\
\text { om a gravação. }\end{array}$ \\
\hline
\end{tabular}

Figura 3: Atividades propostas no Google Classroom. Fonte: dados da pesquisa.

Sobre as habilidades do regente, as respostas finais dos questionários marcadas por todos os participantes apontaram em primeiro lugar que o regente deve possuir bons conhecimentos musicais; em segundo lugar, com $88,9 \%$ das respostas, apareceu a habilidade de comunicação; e em terceiro lugar, com 83,33\% das respostas, foram indicadas as habilidades liderança, criatividade e ser atento às necessidades dos coristas/bom ouvinte. 
Quanto à importância das interações e do espírito colaborativo no coral observou-se que os participantes se auxiliaram mutuamente nas atividades relacionadas às TIC no laboratório de informática e nas eventuais dificuldades de instalação e de uso de programas encontradas por alguns participantes. Durante o período da aplicação o coro fez a organização de uma apresentação de forma colaborativa e o ambiente virtual contribuiu muito no preparo e na execução das atividades relacionadas ao evento.

\section{Ampliação do universo musical e cultural do coro}

Essa categoria foi analisada a partir da atividade realizada com o YouTube relativa à apreciação de músicas e pesquisa dos períodos que foram da Renascença ao pós-modernismo e das tarefas de estudo com os programas Audacity e MuseScore propostas no ambiente presencial e virtual. Foram consideradas as respostas do questionário sobre a utilização de dispositivos tecnológicos para ouvir, conhecer novas músicas, para aprendizagem musical e para uso diário no cotidiano.

Nas respostas finais da questão fechada sobre os aspectos nos quais o coral poderia evoluir com a utilização de tecnologias digitais nos ensaios e nas atividades on-line, todos os integrantes assinalaram as opções "Acesso às informações" e "Aprendizagem de novas músicas". Os itens "Agilidade na comunicação" e "Melhoria da percepção musical" obtiveram 94,4\% das respostas.

\section{A APLICAÇÃO DE TECNOLOGIAS DIGITAIS E O MODELO TPACK}

O emprego das TIC neste trabalho considerou o Conhecimento do Conteúdo que se refere aos conceitos musicais e vocais pertinentes ao canto coral, o Conhecimento Pedagógico que indica a maneira como o educador lida com as práticas de ensino e aprendizagem e o Conhecimento Pedagógico do Conteúdo, no qual foram oportunizadas diferentes estratégias de ensino musical.

O Conhecimento Tecnológico aponta a adaptação e utilização da tecnologia da informação de forma produtiva. Na articulação com o Conhecimento Tecnológico do Conteúdo, os programas MuseScore, Audacity, Solfege e Windows Media Player foram utilizados nos ambientes presencial e virtual como recursos de ensino de elementos que promoveram o desenvolvimento da percepção musical. O software Audacity foi referido por Bauer (2010) em pesquisa de utilização em aulas de música e ensaios e relacionado ao modelo TPACK nos processos de criação, execução e apreciação.

Mishra, Koehler e Henriksen (2011) ressaltam que o Conhecimento Tecnológico Pedagógico está relacionado ao reaproveitamento de tecnologias digitais que podem inicialmente não ter sido desenvolvidas com propósitos pedagógicos, mas que podem ser aproveitadas para fins educacionais.

A interligação entre o Conhecimento do Conteúdo, o Conhecimento Pedagógico e o Conhecimento Tecnológico, que constitui o modelo TPACK, bem como o resumo da integração entre o Conteúdo, a Pedagogia, a Tecnologia digital e o Desenvolvimento musical é demonstrado no Quadro 2 a seguir. 


\begin{tabular}{|c|c|c|c|}
\hline $\begin{array}{c}\text { Tecnologia } \\
\text { digital }\end{array}$ & Conteúdo & Pedagogia & $\begin{array}{c}\text { Desenvolvimento } \\
\text { musical }\end{array}$ \\
\hline MuseScore & $\begin{array}{c}\text { Notação musical, } \\
\text { transposição }\end{array}$ & $\begin{array}{c}\text { Partitura como } \\
\text { um gráfico }\end{array}$ & $\begin{array}{c}\text { Criação, apreciação } \\
\text { e técnica }\end{array}$ \\
\hline Audacity & $\begin{array}{c}\text { Aspectos vocais, } \\
\text { estudo do repertório }\end{array}$ & Estudo e reflexão & $\begin{array}{c}\text { Apreciação, técnica } \\
\text { e execução }\end{array}$ \\
\hline Solfege & Figuras musicais & Vivência rítmica & Técnica e execução \\
\hline $\begin{array}{c}\text { Windows } \\
\text { Media Player }\end{array}$ & $\begin{array}{c}\text { Repertório, novas } \\
\text { canções }\end{array}$ & Estudo e reflexão & $\begin{array}{c}\text { Apreciação } \\
\text { e literatura }\end{array}$ \\
\hline $\begin{array}{c}\text { Google } \\
\text { Classroom }\end{array}$ & $\begin{array}{c}\text { Organização do } \\
\text { material e atividades }\end{array}$ & $\begin{array}{c}\text { Estudo, interação } \\
\text { e reflexão }\end{array}$ & $\begin{array}{c}\text { Apreciação, literatura, } \\
\text { criação, técnica } \\
\text { e execução }\end{array}$ \\
\hline YouTube & $\begin{array}{c}\text { Canções tradicionais } \\
\text { do mundo e periodos } \\
\text { da História da Música }\end{array}$ & $\begin{array}{c}\text { Estudo, reflexão } \\
\text { e ampliação do } \\
\text { universo musical }\end{array}$ & $\begin{array}{c}\text { Apreciação, literatura } \\
\text { e técnica }\end{array}$ \\
\hline
\end{tabular}

Quadro 2: Aplicação do TPACK à prática coral. Fonte: dados da pesquisa.

Em relação ao processo de articulação das TIC com o modelo TPACK na educação musical Mroziak e Bowman (2016, p. 419, tradução nossa) afirmam que este

envolve integração da tecnologia no ensino e aprendizagem da música através das principais maneiras pelas quais as pessoas se envolvem com a música - criando (compondo, improvisando), executando (cantando) e respondendo (ouvindo, analisando)..$^{23}$

\section{CONSIDERAÇÕES FINAIS}

A aplicação das TIC na prática coral a partir do modelo TPACK foi uma experiência que serviu de suporte ao trabalho da regente e colaborou com o desenvolvimento do coro em vários aspectos. A utilização de cada tecnologia específica fundamentada nas interseções entre o Conhecimento do Conteúdo, o Conhecimento Pedagógico e o Conhecimento Tecnológico contribuiu de diferentes maneiras no processo de ensino e aprendizagem musical dos coristas.

\footnotetext{
23 "It involves integrating technology into the teaching and learning of music through the major ways that people engage with music - through creating (composing, improvising), performing (singing) and responding (listening to, analyzing)."
} 
O software MuseScore possibilitou um contato de forma visual e ao mesmo tempo sonoro com o repertório permitindo que os coristas pudessem observar e perceber conceitos e elementos musicais. As atividades possibilitaram um contato gradual com a notação musical e a criação de pequenas melodias. A utilização do programa MuseScore auxiliou no ensino e aprendizagem de novas canções e na compreensão de conceitos musicais tais como altura, duração e transposição de tons.

A utilização do Audacity na prática coral possibilitou o desenvolvimento da percepção musical e da produção vocal dos coristas. No ambiente virtual, o Audacity funcionou como um recurso que contribuiu com o aperfeiçoamento vocal dos integrantes. As gravações postadas na sala virtual possibilitaram o acompanhamento individualizado e o feedback da regente. Os programas Audacity e Windows Media Player colaboraram com reflexões produzidas a partir da análise das gravações do próprio coro e de coros-referência. A partir do Windows Media Player foram propostos diálogos sobre elementos tais como sonoridade, expressão corporal, colocação vocal, entre outros.

O software GNU Solfege foi aplicado nos ensaios presenciais no formato de um jogo musical de ritmo onde os integrantes puderam perceber figuras musicais na forma visual e sonora e vivenciá-las corporalmente. O GNU Solfege permitiu o contato dos coristas com as figuras musicais de forma lúdica e interativa. O propósito da utilização do YouTube foi promover o conhecimento, a pesquisa e a contextualização de canções de diferentes períodos da história da música. A tecnologia do YouTube possibilitou o contato com músicas de diferentes culturas e períodos, fato que contribuiu com a ampliação do universo musical do coro.

A sala virtual Google Classroom foi o ambiente usado para integrar o material de partituras e de áudios no formato mp3 e para a realização e postagem das tarefas propostas aos coristas durante a semana. $\mathrm{O}$ ambiente virtual cooperou com a organização do material de estudo do coro e com a postagem de atividades. A sala virtual favoreceu a interação entre a regente e os coristas, dos coristas entre si e o estudo durante a semana. Ao organizar todo o material de trabalho no ambiente virtual o regente poderá ter beneficios, tais como agilidade no compartilhamento de arquivos, maior facilidade de interação com o seu coro, armazenamento e recuperação de informações de forma mais rápida, entre outros.

O uso das TIC na prática coral pode contribuir com o desenvolvimento da percepção musical e com a ampliação do universo musical e cultural do grupo, bem como promover a reflexão dos integrantes e desse modo levar o coro para o próximo nível de desafios. Além disso o regente pode valer-se de recursos para interagir de forma individual com os seus coristas, buscando desenvolver o potencial de cada um e consequentemente de seu coro, ao máximo. As TIC possibilitam a aplicação de múltiplas oportunidades para que os individuos se relacionem e vivenciem a música de diferentes formas. 


\section{REFERENCIAS}

BAUER, William. Technological pedagogical and content knowledge for music teachers. In: SOCIETY FOR INFORMATION TECHNOLOGY \& TEACHER EDUCATION INTERNATIONAL CONFERENCE, 17. 2010, San Diego. Proceedings [...] Waynesville: Association for the Advancement of Computing in Education, 2010. p. 3977-3980.

Music learning today: digital pedagogy, performing and responding music. New York: Oxford University Press, 2014.

BAUER, William; MITO, Hiromichi. ICT in music education. In: KING, Andrew; HIMONIDES, Envangelos; RUTHMANN, S. Alex (ed.). The Routledge companion to music, technology, and education. New York: Routledge, 2017. p. 91-102.

BRITO, Teca Alencar de. Hans-Joachim Koellreutter: a música e a educação em um novo mundo. In: MATEIRO, Teresa; ILARI, Beatriz (org.). Pedagogias brasileiras em educação musical. Curitiba: Intersaberes, 2016. p. 139-160.

CLEMENTE, Louise; FIGUEIREDO, Sérgio Luiz Ferreira de. O estado da arte da pesquisa sobre canto coral no Brasil e os principais temas relacionados à Educação Musical coral. In: ENCONTRO REGIONAL SUL DA ABEM, 16., 2014, Blumenau. Anais [...] Blumenau: Abem, 2014.

CRESWELL, John W. Projeto de pesquisa: métodos qualitativo, quantitativo e misto. Tradução de Magda Lopes. Porto Alegre: Artmed, 2010.

DEMO, Pedro. Olhar do educador e novas tecnologias. Boletim Técnico do Senac: a Revista da Educação Profissional, Rio de Janeiro, v. 37, n. 2, p. 15-26, 2011.

DOEBELE, Alexa. Technology and the choral art: music in the cloud for the modern choral director. The Choral Journal, Oklahoma City, v. 53, n. 5, p. 91-95, 2012.

FREITAS, Sara de; CONOLE, Gráinne. The influence of pervasive and integrative tools on learners experiences and expectations of study. In: SHARPE, Rhona; BEETHAM, Helen; FREITAS, Sara. Rethinking learning for a digital age: how learners are shaping their own experiences. New York: Routledge, 2010. p. 15-30.

GIL, Antônio Carlos. Métodos e técnicas de pesquisa social. São Paulo. Atlas, 2007.

GOHN, Daniel Marcondes. Tecnologias digitais para educação musical. São Carlos: EdUFSCar, 2010. 
ILARI, Beatriz. A música e o cérebro: algumas implicações do neurodesenvolvimento para a educação musical. Revista da Abem, Porto Alegre, n. 9, p. 7-16, set. 2003.

KERI, Facer; SELWYN, Neil. Social networking. Key messages from the research. In: SHARPE, Rhona; BEETHAM, Helen; FREITAS, Sara. Rethinking learning for a digital age: how learners are shaping their own experiences. New York: Routledge, 2010. p. 31-42.

KOEHLER, Matthew J.; MISHRA, Punya. What is technological pedagogical content knowledge. Contemporary Issues in Technology and Teacher Education, [s. l.], v. 9, n. 1, p. 60-70, 2009.

KRUMHANSL, Carol L. Ritmo e altura na cognição musical. In: ILARI, Beatriz (org.). Em busca da mente musical: ensaios sobre os processos cognitivos em música - da percepção à produção. Curitiba: Editora da UFPR, 2006. p. 45-109.

LEVITIN, Daniel. J. This is your brain on music: the science of a human obsession. New York: Dutton, 2006.

MATEIRO, Teresa; VECHI, Hotênsia; DE SOUZA EGG, Marisleusa. A prática do canto na escola básica: o que revelam as publicações da ABEM (19922012). Revista da Abem, Londrina, v. 22, n. 33, p. 57-76, 2014.

MILETTO, Evandro M.; COSTALONGA, Leandro L.; FLORES, Luciano V.; FRITSCH, Eloi F.; PIMENTA, Marcelo S.; VICARI, Rosa M. Educação Musical auxiliada por computador. Algumas considerações e experiências. Renote: Revista Novas Tecnologias na Educação, Porto Alegre, v. 2, n.1, mar. 2004. Sem paginação.

MISHRA, Punya; KOEHLER, Matthew J. Technological pedagogical content knowledge: a framework for teacher knowledge. Teachers College Record, New York, v. 108, n. 6, p. 1017-1054, 2006.

MISHRA, Punya; KOEHLER, Matthew J.; HENRIKSEN, Danah. The seven transdisciplinary habits of mind: extending the TPACK framework towards 21st century learning. Educational Technology, Englewood Cliffs, v. 51, n. 2, p. 22-28, 2011.

MROZIAK, Jordan; BOWMAN, Judith. In: HERRING, Mary C.; KOEHLER, Matthew J.; MISHRA, Punya (ed.). Handbook of technological pedagogical content knowledge (TPACK) for educators. New York: Routledge, 2016. p. 419-434.

SALAVUO, Miikka. Social media as an opportunity for pedagogical change in music education. Journal of Music Technology and Education, Bristol, v. 1, n. 2-3, p. 121-136, 2008. 
SANTOS, Bruno Silva. O canto coral na educação musical: análise e catalogação a partir das publicações nos anais da ABEM e da ANPPOM, e na Revista da ABEM e Revista OPUS (2009 a 2013). 2014. Trabalho de Conclusão de Curso (Licenciatura em Música) - Escola de Música, Universidade Federal do Rio Grande do Norte, Natal, 2014.

SCHAFER, Murray. R. O ouvido pensante. Tradução de Marisa Trench Fonterrada. São Paulo: Editora da Unesp, 1991.

SOBREIRA, Silvia. Desafinação vocal. Rio de Janeiro: MusiMed, 2003.

SWANWICK, Keith. A basis for music education. London: Nfer-Nelson, 1979.

TRIPP, David. Pesquisa-ação: uma introdução metodológica. Educação e Pesquisa, São Paulo, v. 31, n. 3, p. 443-466, 2005.

VELlOSO, Fernando Castro. Informática: conceitos básicos. 9. ed. Rio de Janeiro: Elsevier Brasil, 2014.

VINCENT, Marilyn C.; MERRION, Margaret. Teaching music in the year 2050. Music Educators Journal, [s. l.], v. 82, n. 6, p. 38-42, 1996. 
Sandra Regina Cielavin é doutoranda e mestra em Música pela Universidade Estadual de Campinas (Unicamp). Licenciada em Educação Musical pela Universidade Federal de São Carlos (UFSCar). Possui pós-graduação em Psicopedagogia e graduação em Tecnologia em Processamento de Dados pela Faculdade de Tecnologia de Sorocaba (Fatec-SO). Formou-se em piano erudito no Conservatório Dramático e Musical Dr. Carlos de Campos, onde estudou canto, piano popular e regência coral. É professora da Faculdade de Tecnologia de Itapetininga, Centro Paula Souza (Ceeteps) na área de Ciência da Computação e regente do Coral Fatec Itapetininga. https://orcid.org/0000-0002-8672-0038

Adriana do Nascimento Araújo Mendes é doutora em Música na área de Fundamentos Teóricos pela Universidade Estadual de Campinas (Unicamp), mestre em Música pela Syracuse University, EUA e bacharel em Piano pela Universidade Federal do Rio de Janeiro (UFRJ). É professora do curso de Graduação em Música e do Programa de Pós-Graduação em Música da Unicamp, onde ministra disciplinas da área de Educação Musical e desenvolve pesquisas sobre a formação do professor de música, com ênfase em "Tecnologias e ensino musical", "Pibid", "Ensino musical e inclusão", "Estágio supervisionado" e "Ensino coletivo de piano". Atualmente é coordenadora do Curso de Graduação em Música da Unicamp - Bacharelado e Licenciatura. É coordenadora de área do Pibid Arte Unicamp e coordenadora do projeto de extensão "Oficina de Musicalização", desde 2009. É membro da Isme, Abem e Anppom e é integrante do grupo de pesquisa Tecnologias Aplicadas à Criação, à Expressão e ao Ensino Musicais. https://orcid.org/0000-0002-9730-2202 